CYSTIC FIBROSIS

\title{
Effect of oral bisphosphonates on bone mineral density and body composition in adult patients with cystic fibrosis: a pilot study
}

\author{
S P Conway, B Oldroyd, A Morton, J G Truscott, D G Peckham
}

Thorax 2004;59:699-703. doi: 10.1136/thx.2002.002568

See end of article for authors' affiliations

Correspondence to:

Dr S P Conway, Regional

Cystic Fibrosis Unit,

Seacroft Hospital, Leeds

LS14 6UH, UK; steven.

conway@leedsth.nhs.uk

Received 5December 2002

Accepted 13 April 2004
Background: Approximately two thirds of adult patients with cystic fibrosis have reduced bone mineral density and up to one quarter have osteoporosis at one or more sites. Any bone mineral deficits are likely to be exacerbated in patients following lung transplantation by their immunosuppressive regimen. Vertebral collapse and rib fractures will impair the ability to cough and the efficacy of physiotherapy treatments.

Methods: Patients attending the Leeds Regional Adult Cystic Fibrosis Unit with either osteopenia or osteoporosis on dual energy $x$ ray absorptiometry (DXA) scanning were offered treatment with oral bisphosphonates after exclusion of abnormal vitamin D, calcium, or phosphate levels, abnormal thyroid function, or hypogonadism. Those declining treatment or patients with a normal initial DXA scan formed the control group. A second DXA scan was performed after a mean of 2.4 years in the treatment group and 2.9 years in the non-treatment group. Patients in the active group were asked to complete a short questionnaire detailing their adherence to treatment.

Results: The medians of the differences in annual changes in bone parameters between treatment and control groups showed significant differences in bone mineralisation in favour of the treatment group at the lumbar spine (L2-L4), the femoral neck, and for total body measurements. There were no significant differences in weight, height, or body composition in either patient group. Most treated patients stated that they adhered to treatment most of the time.

Conclusion: Treatment with oral bisphosphonates may improve bone mineralisation in adult patients with cystic fibrosis. The results of this pilot study need to be further explored in a randomised controlled trial.
$\mathrm{B}$ oth children and adults with cystic fibrosis (CF) may have inadequate bone mineralisation even when growth and nutrition are reasonably well maintained. ${ }^{1}$ Many factors such as malabsorption, delayed puberty, hypogonadism, reduced weight bearing activity, corticosteroid use, and acute or chronic lung inflammation contribute to the increased prevalence of osteopenia and osteoporosis in these patients. ${ }^{2-5}$ The possible end results are kyphosis and an increased risk of fractures, ${ }^{67}$ either of which may significantly impact on quality of life and lung function. Patients with severe CF lung disease are at particular risk of osteoporosis. ${ }^{8} 9$ Those referred for lung transplantation show vertebral compression and rib fractures 100 and 10 times, respectively, more often than expected. ${ }^{7}$

Deficits in bone mineralisation occur following an imbalance between bone formation and resorption and are related to a combination of decreased bone osteoblast numbers and an increase in osteoclast activity. ${ }^{40}{ }^{11}$ Biochemical data suggest that increased bone resorption may be the predominant event in prepubertal, pubertal, and young adult patients. ${ }^{10}$ Alterations in bone metabolism are also associated with acute respiratory exacerbations, chronic lung inflammation, and infection. Serum osteocalcin levels may return to normal following the treatment of acute respiratory exacerbations, but urinary $\mathrm{N}$-telopeptide and deoxypyridinoline-which are markers of continued bone resorption-may remain raised. ${ }^{4}$

Bisphosphonates have been shown to reduce osteoclast induced bone resorption and have been widely used in people without CF for both treatment and prophylaxis of osteoporosis. $^{12}{ }^{13}$ The clinical response to treatment can be monitored using dual energy $x$ ray absorptiometry (DXA). This provides a precise method of measuring small changes in bone mineral density (BMD) at the lumbar spine, femoral neck, and total body sites. The technique can also be used to estimate changes in a three compartment analysis of body composition, total body lean tissue (TBLean), total body fat (TBF), and total body bone mineral content (TBBMC).

The aim of this study was to monitor the effects of treatment with bisphosphonates on bone mineral density (BMD), bone mineral content (BMC) and area, and on body composition in young adults with CF.

\section{METHODS}

\section{Study design}

In a prospective open study, patients with baseline DXA scans showing osteopenia or osteoporosis at the lumbar spine, femoral neck, or for total body BMD were informed of their DXA scan result and offered treatment with either alendronate $10 \mathrm{mg}$ once daily and sandocal $400 \mathrm{mg}$ once daily, or disodium etidronate (as didronel PMO, including $500 \mathrm{mg}$ calcium). Patients who accepted bisphosphonate treatment formed the treatment group and those who declined treatment or had normal first scans formed the control group. Comparisons were made between the treatment and control groups for potential confounding factors; corticosteroid and oral contraceptive use, serum vitamin D levels, number of hospital admissions, and changes in percentage predicted forced expiratory volume in 1 second $\left(\mathrm{FEV}_{1}\right)$ over the study period.

Abbreviations: $B M C$, bone mineral content; $B M D$, bone mineral density; CF, cystic fibrosis; TBBMC, total body bone mineral content; TBF, total body fat; TBLean, total body lean tissue 
Osteopenia was defined for adolescents (16.3-19.5 years of age) and for adults as an age and sex matched Z score 12.5 SD below the mean. Osteoporosis was similarly defined as an age and sex matched $\mathrm{Z}$ score $>2.5$ SD below the mean. Those treated with oral bisphosphonates were asked to answer a short questionnaire about their adherence to treatment with the response ranging from "never" to "always" taking the medication. At each outpatient follow up visit patients in the treatment group were asked about any adverse events associated with the bisphosphonate treatment.

\section{Subjects}

One hundred and fourteen patients underwent baseline DXA scanning, $76(67 \%)$ of whom showed either osteopenia or osteoporosis. ${ }^{3}$ These patients were screened for abnormalities of thyroid or liver function, hypogonadism, and low serum calcium, phosphate and vitamin D levels, all of which may compromise BMD. Thirty five patients (20 male) agreed to receive bisphosphonate treatment and to enter the study. Twenty four patients (eight male) were recruited to the control group. No further patients were entered into the study because of restricted access to the DXA scanner. The demographic characteristics of the 59 study patients and the 55 patients who had baseline DXA scanning but did not take part in this follow up study are shown in table 1 . At the start of treatment there were 11 adolescents in both the treatment and control groups (age range 16.3-19.4 and 16.8-19.2 years, respectively). The 55 patients who had baseline DXA scans but did not participate in the study included 15 adolescents in a similar age range. At follow up only two patients in the treatment group and three in the non-treatment group were classed as adolescents. All patients had characteristic radiological and clinical features of CF and had been diagnosed by two positive sweat test results and/or identification of two cystic fibrosis transmembrane regulator gene mutations.

\section{Bone mineral density and body composition measurements}

The study patients had a second DXA scan at a mean of 32 months (range 13-63) after the initial assessment. BMD,
BMC, and area were measured at the lumbar spine (L2-L4), right femoral neck, and total body using a DPX-L densitometer (Ge/Lunar). Body composition was determined from the total body scan consisting of lean tissue (TBLean), fat (TBF), \%TBF, and bone mineral (TBBMC). Patient scans were analysed using software analysis version 4.3c. Extended research analysis was used for all patient total body scans. Since the study groups included both adolescents and adult patients, Z scores were used. For adult patients age matched $\mathrm{Z}$ scores were derived from the manufacturers' UK reference ranges and for adolescents age matched $\mathrm{Z}$ scores were derived from the manufacturers' USA white children reference ranges. Short term in vivo precision for the three BMD measurement sites were $1.2 \%, 1.5 \%$, and $0.8 \% .{ }^{14}$ Body composition short term in vivo precision for TBlean, TBF, \%TBF, and TBBMC were $1.0 \%, 2.9 \%, 2.9 \%$, and $1.7 \%$, respectively. ${ }^{15}$ Long term (3.5 years) in vitro precision for lumbar spine (L2L4) using the manufacturers' aluminium spine was $0.5 \%$. Using a total body phantom the long term precision ( 3 years) for TBBMD, TBBMC, and \%TBF was $0.8 \%, 1.5 \%$, and $4.7 \%$, respectively. ${ }^{16}$

\section{Vitamin D supplement protocol}

All pancreatic insufficient patients attending the Leeds CF unit receive a minimum of 800 IU vitamin D daily with dose adjustment according to serum levels measured at the annual review. At the commencement of the study a vitamin D level of $>15 \mathrm{ng} / \mathrm{ml}$ was accepted as adequate. From October 2001 the lower acceptable limit was increased to $20 \mathrm{ng} / \mathrm{ml}$.

\section{Statistical analysis}

Statistical analyses were performed with Minitab version 9.1 (Minitab Inc, PA, USA). Results were expressed as mean (SD) or median (95\% CI). Anderson Darling statistical tests were performed to determine if the data were normally distributed. Percentage changes were avoided because of the potential bias of smaller baseline BMD values giving higher percentage changes for the same absolute change in BMD. Absolute differences between baseline and follow up were therefore normalised for follow up time to compare annual

\begin{tabular}{|c|c|c|c|c|c|}
\hline & \multicolumn{2}{|c|}{ Treatment group ( $n=35$ ) } & \multicolumn{2}{|c|}{ Control group $(n=24)$} & \multirow{2}{*}{$\begin{array}{l}\text { Non-study group } \\
(\mathrm{n}=55)\end{array}$} \\
\hline & Baseline & Follow up & Baseline & Follow up & \\
\hline Age (years) & $24.7(6.2)$ & $27.0(6.3)$ & $21.4(4.0)^{*}$ & $24.3(4.7)$ & $24.5(6.3)$ \\
\hline Height $(\mathrm{cm})$ & $165.7(8.5)$ & $166.3(8.9)$ & $164.7(9.7)$ & $164.3(9.2)$ & $164.5(8.1)$ \\
\hline Weight (kg) & $55.6(8.9)$ & $55.9(10.0)$ & $55.3(10.4)$ & $55.9(10.1)$ & $52.7(8.4)$ \\
\hline BMI $\left(\mathrm{kg} / \mathrm{m}^{2}\right)$ & $20.2(2.1)$ & $20.1(2.3)$ & $20.3(2.5)$ & $20.6(2.2)$ & $19.4(2.4)$ \\
\hline \multicolumn{6}{|l|}{$\begin{array}{l}\text { Duration of } \\
\text { treatment (years) }\end{array}$} \\
\hline $\operatorname{Sex}(F / M)$ & $15 / 20$ & & $16 / 8$ & & $30 / 25$ \\
\hline \multicolumn{6}{|l|}{ PA spine (L2-L4) } \\
\hline$B M C(g)$ & $41.0(8.4)$ & $43.4(9.6)$ & $45.6(9.3)$ & $45.9(8.9)$ & $42.5(8.2)$ \\
\hline Area $\left(\mathrm{cm}^{2}\right)$ & $40.6(5.0)$ & $41.5(5.3)$ & $40.1(5.5)$ & $40.3(5.4)$ & $40.0(4.4)$ \\
\hline$B M D\left(\mathrm{~g} / \mathrm{cm}^{2}\right)$ & $1.001(0.12)$ & $1.035(0.13)$ & $1.131(0.10) \mathrm{t \dagger}$ & $1.132(0.10)$ & $1.059(0.14)$ \\
\hline Z score & $-1.8(1.0)$ & $-1.5(1.1)$ & $-0.7(1.0)+\dagger$ & $-0.7(0.8)$ & $-1.2(1.2)$ \\
\hline \multicolumn{6}{|l|}{ Femoral neck } \\
\hline$B M C(g)$ & $4.2(0.8)$ & $4.3(0.7)$ & $4.7(0.7)$ & $4.5(0.7)$ & $4.3(0.8)$ \\
\hline Area $\left(\mathrm{cm}^{2}\right)$ & $4.6(0.5)$ & $4.7(0.5)$ & $4.5(0.5)$ & $4.5(0.5)$ & $4.5(0.4)$ \\
\hline BMD $\left(\mathrm{g} / \mathrm{cm}^{2}\right)$ & $0.911(0.13)$ & $0.910(0.11)$ & $1.029(0.08) \mathrm{tt}$ & $0.987(0.08)$ & $0.948(0.15)$ \\
\hline Z score & $-1.1(1.0)$ & $-1.0(0.8)$ & $0.0(0.6) \ddagger$ & $-0.3(0.6)$ & $-0.8(1.2)$ \\
\hline \multicolumn{6}{|l|}{ Total body } \\
\hline$B M C(g)$ & $2164(384)$ & $2238(438)$ & $2290(469)$ & $2267(462)$ & $2146(411)$ \\
\hline Area $\left(\mathrm{cm}^{2}\right)$ & $1984(255)$ & $2003(279)$ & $2009(285)$ & 1997 (278) & $1963(254)$ \\
\hline BMD $\left(\mathrm{g} / \mathrm{cm}^{2}\right)$ & $1.084(0.07)$ & $1.110(0.08)$ & $1.131(0.08)$ & $1.128(0.08)$ & $1.086(0.09)$ \\
\hline Z score & $-1.15(0.9)$ & $-0.9(0.9)$ & $-0.4(0.8) \dagger$ & $-0.4(0.7)$ & $-0.8(1.2)$ \\
\hline
\end{tabular}

$\mathrm{BMD}=$ bone mineral density; $\mathrm{BMC}=$ bone mineral content; $\mathrm{BMI}=$ body mass index

${ }^{*} \mathrm{p}<0.005$ significantly younger than treatment/non-study group.

$t p<0.05,+\uparrow p<0.0001$ significantly higher than treatment group

$\neq p<0.005$ significantly higher than treatment/non-study groups. 
changes in bone parameters. One way analysis of variance (ANOVA) with Tukey's test was used to compare the baseline characteristics of the three groups with Kruskal-Wallis ANOVA used for non-parametric data. Mann-Whitney tests were used to compare annual changes in bone parameters and Spearman's rank correlations were used to examine associations between annual changes in bone parameters and confounding factors. A p value of $<0.05$ was considered statistically significant.

\section{RESULTS}

Absolute values at baseline and follow up of the physical characteristics and bone parameters of the groups are shown in table 1 . There were no significant differences in height, weight, or BMI between baseline and follow up in either group. Body composition measurements at baseline and follow up for the treatment and control groups were: TBLean (kg) 42.1 (8.7) and 42.0 (8.9) v 41.1 (9.8) and 41.5 (10.2); TBFat (kg) $11.4(3.6)$ and $11.5(4.5) v 11.9(5.9)$ and 12.2 (5.7); \%TBF 20.8 (6.1) and 20.7 (7.3) v 21.5 (10.1) and 21.9 (9.4). The mean (SD) follow up time interval for the con trol group of 2.9 (1.1) years was significantly longer than that observed for the treatment group of $2.4(0.6)$ years $(\mathrm{p}=0.001)$.

The medians of the differences between the annual changes in bone parameters in the treatment and control groups were significant at all three sites (fig 1, table 2). These showed significant gains in BMC and Z scores at the lumbar spine, in BMC, BMD and Z scores at the femoral neck, and in BMC and BMD at the total body for the treatment group. There was no significant correlation with age at baseline and annual change of BMD at any of the three sites.

Six patients switched from daily alendronate to didronel PMO because of difficulties adhering to the precautions necessary to minimise the risk of oesophageal problems associated with the former. One patient switched from daily to weekly alendronate. Two patients stopped their bisphosphonate treatment because they did not want any more daily medication. Two patients stopped treatment because of nausea, vomiting, and/or heartburn. Three patients suffered bone pain with alendronate; two settled with 3 monthly intravenous pamidronate and one with didronel PMO.

No significant differences were found between the treatment and control groups at the beginning or end of the study period in serum vitamin D levels or in percentage predicted $\mathrm{FEV}_{1}$ values. There were no differences between the groups in the number of courses of intravenous antibiotic treatments

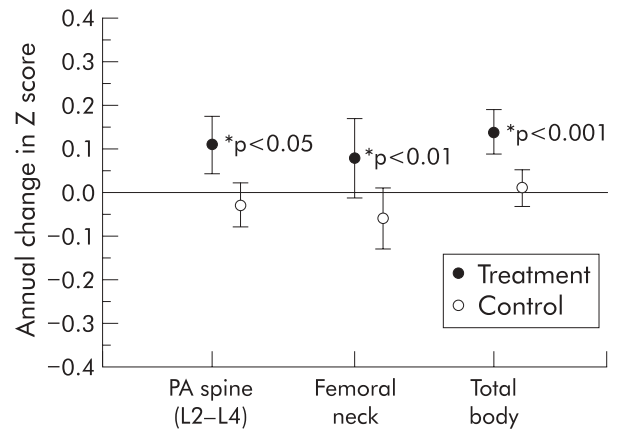

Figure 1 Annual change in Z scores at the three sites. Values are median $(95 \% \mathrm{Cl})$. *Significantly higher than control group.

received, oral or inhaled corticosteroid prescriptions, or number of women taking an oral contraceptive pill.

One patient in each group was pancreatic sufficient. Eleven of 35 in the treatment group and eight of 24 in the control group had CF related diabetes mellitus at the time of their first DXA scan. Corresponding numbers at the end of the study were 16 of 35 and 10 of 24 . In the treatment group one patient at the start and two at the end of the study had had a bilateral lung transplant.

Questionnaires were returned from 32 treated patients; 21 (12 male) said that they took the bisphosphonate treatment almost all of the time or most of the time. Seven ( 3 male) said that they never or "not very often" took their treatment.

\section{DISCUSSION}

This study shows that treatment of adult patients with CF with oral bisphosphonates for 2-3 years may improve bone mineralisation. Similar results have been shown with renal transplant patients treated with alendronate. ${ }^{17}$

Osteoporosis in CF is the result of an imbalance in bone formation and resorption. Better care of the present generation of children with CF with, for example, optimal nutritional management, exercise, and prompt treatment of infective exacerbations has reduced the prevalence of bone disease in this age group. ${ }^{18} 19$ Conversely, studies in large unselected populations of adults with CF have shown that between one third and two thirds of patients have significantly reduced BMD. ${ }^{23}$ Haworth et al reported a prospective study of change in BMD in adult patients. ${ }^{20}$ In those aged 24 years and younger-a time when a small annual increase

\begin{tabular}{|c|c|c|c|}
\hline & Treatment group $(n=35)$ & Control group ( $n=24$ ) & $\begin{array}{l}\text { Difference between } \\
\text { population medians }\end{array}$ \\
\hline \multicolumn{4}{|l|}{ PA spine (L2-L4) } \\
\hline$B M C(g)$ & $0.59(0.14$ to 1.21$)$ & $0.18(-0.21$ to 0.45$)$ & $0.62^{*}(-0.01$ to 1.34$)$ \\
\hline Area $\left(\mathrm{cm}^{2}\right)$ & $0.29(0.21$ to 0.42$)$ & $0.16(-0.10$ to 0.34$)$ & $0.18(-0.05$ to 0.40$)$ \\
\hline $\mathrm{BMD}\left(\mathrm{g} / \mathrm{cm}^{2}\right)$ & 0.008 (0.003 to 0.018$)$ & $-0.004(-0.005$ to 0.005$)$ & $0.011(-0.001$ to 0.022$)$ \\
\hline Z score & 0.11 (0.05 to 0.18 ) & $-0.03(-0.05$ to 0.05$)$ & $0.12^{*}(0.03$ to 0.21$)$ \\
\hline \multicolumn{4}{|l|}{ Femoral neck } \\
\hline$B M C(g)$ & $0.01(-0.02$ to 0.07$)$ & $-0.08(-0.10$ to -0.04$)$ & $0.09^{* *}(0.05$ to 0.15$)$ \\
\hline Area $\left(\mathrm{cm}^{2}\right)$ & $0.02(0.00$ to 0.04$)$ & 0.005 (0.00 to 0.02 ) & $0.02(-0.01$ to 0.04$)$ \\
\hline $\mathrm{BMD}\left(\mathrm{g} / \mathrm{cm}^{2}\right)$ & $-0.001(-0.01$ to 0.009$)$ & $-0.014(-0.021$ to -0.010$)$ & $0.014^{* *}(0.004$ to 0.25$)$ \\
\hline Z score & $0.08(-0.01$ to 0.17$)$ & $-0.06(-0.18$ to -0.04$)$ & $0.16^{* *}(0.06$ to 0.27$)$ \\
\hline \multicolumn{4}{|l|}{ Total body } \\
\hline$B M C(g)$ & $15.9(3.1$ to 41.7$)$ & $1.0(-24.4$ to 13.9$)$ & $30.0^{* *}(8.5$ to 59.0$)$ \\
\hline Area $\left(\mathrm{cm}^{2}\right)$ & $0.69(-8.7$ to 18.9$)$ & $2.5(-10.5$ to 11.2$)$ & $6.9(-7.2$ to 28.6$)$ \\
\hline $\mathrm{BMD}\left(\mathrm{g} / \mathrm{cm}^{2}\right)$ & $0.011(0.006$ to 0.013$)$ & $0.001(-0.003$ to 0.004$)$ & $0.010^{* * * *}(0.006$ to 0.017$)$ \\
\hline Z score & $0.14(0.08$ to 0.16$)$ & $0.01(-0.04$ to 0.04$)$ & $0.13^{* * *}(0.07$ to 0.20$)$ \\
\hline
\end{tabular}


in BMD is expected before peak bone mass is reached-there was an annual fall in BMD in the axial skeleton. In subjects aged 25 years and above, when BMD is expected to remain stable, there was an annual fall in BMD at the femoral neck, hip, and distal forearm. BMD pathology in patients with CF seems to involve both inadequate bone mineral accretion and excessive bone loss. An effective treatment is needed to prevent the morbidity and premature mortality that will result from osteoporosis associated fractures and vertebral collapse. Transplant centres are requesting DXA scans at referral and treatment of patients with low BMD. Among other possible therapeutic approaches, Haworth et al suggest bisphosphonate therapy. ${ }^{20}$

Bisphosphonates inhibit osteoclast function and possibly stimulate osteoblast activity. ${ }^{21}{ }^{22}$ They are licensed for the prevention and treatment of postmenopausal and corticosteroid induced osteoporosis in which conditions they have been shown to reduce the fracture rate and increase BMD. ${ }^{12}{ }^{13}$ They may therefore be seen as the natural agents to trial in patients with CF associated BMD problems. Haworth et al ${ }^{23}$ and Aris et $a^{24}$ have reported the efficacy of intravenous pamidronate administered 3 monthly with daily calcium supplements in patients with CF both before and after lung transplantation. The former study was prematurely closed because of pamidronate induced bone pain. Patients in the latter study were probably protected against this adverse event by concurrent corticosteroid treatment received as part of the post-transplant immunosuppressive regimen. It is possible that short term prednisolone prescription around the time of the infusion might avert the bone pain but, if used routinely in adult CF centres, the 3 monthly treatment regimen is likely to cause significant bed occupancy problems.

Patients may not readily accept hospital attendance for intravenous pamidronate treatment, especially if associated with subsequent bone pain, for an asymptomatic complication of their condition. Daily oral bisphosphonates are acceptable to most patients despite the precautions that must be followed to reduce gastrointestinal side effects and aid absorption. $68 \%$ of those who returned their questionnaires reported good adherence to treatment. This should increase with the once weekly dosage preparations now available. Oral bisphosphonates are also cheaper than intravenous preparations.

The conclusions of this study are limited by the fact that it was not a blinded randomised controlled trial. Both adolescents ( $<20$ years of age) and adults were included and some increases in bone mineralisation would be expected in the younger patients through the second decade due to normal bone acquisition. Factors that may affect the accuracy of the measured changes also need to be identified in longitudinal studies of bone mineral density. Anomalies due to changes in weight, bone area, and fat distribution in the lumbar spine region have been reported. ${ }^{25-28}$

In this study heterogenous weight changes were observed-for example, in the treatment group a maximum increase of $9.4 \mathrm{~kg}$ (13\%) and a maximum decrease of $7.2 \mathrm{~kg}$ (11\%) was observed. However, no detectable effect of weight change was observed on the measured bone mineral parameters.

The accuracy of longitudinal changes in bone mineral can be affected if there are appreciable changes in fat distribution in the lumbar spine region. This anomaly, which is difficult to quantify, would affect all groups in the study since gains and losses in TBF were observed in all the patient groups. An artefact of measured area varying with BMC/BMD has also been identified. In this study a significant change of area was observed at the lumbar spine in the treatment group: 40.6 (5.0) $v 41.5$ (5.3), $\mathrm{p}<0.001$. Although small changes may be expected in adolescents, area measurements in adults would be expected to remain constant. The derived equation in this study for change in area at the lumbar spine $(-0.1+0.37$ * change in BMC, $r=0.76, \mathrm{p}<0.0001)$ is in close agreement with the derived equation of Peel and Eastell ${ }^{26}$ (change in area $=0.05+0.30$ * change in $\mathrm{BMC}$ ), also derived on a Ge/ Lunar DPX.

In conclusion, this pilot study suggests that oral bisphosphonates may have a role in the treatment of adult patients with CF with BMD deficits. Many CF treatment protocols are based on anecdotal or small underpowered studies. Because osteoporosis and osteopenia are so prevalent and their consequences so potentially devastating for the patient, physicians are already using various bisphosphonates by oral and intravenous routes as treatment for reduced BMD. This paper shows sufficiently positive results to warrant the funding of an adequately powered multicentre study. The need for this is urgent. If it is not forthcoming bisphosphonate therapy may become another commonly agreed best practice in CF care without our ever knowing if it is of real benefit for all patients.

\section{Authors' affiliations}

S P Conway, A Morton, D G Peckham, Regional Adult Cystic Fibrosis Unit, Leeds Teaching Hospitals NHS Trust, University of Leeds, Leeds, UK B Oldroyd, J G Truscott, Centre for Bone and Body Composition, University of Leeds, Leeds, UK

\section{REFERENCES}

1 Henderson RC, Madsen CD. Bone mineral content and body composition in children and young adults with cystic fibrosis. Pediatr Pulmonol 1999;27:80-4

2 Haworth CS, Selby PL, Webb AK, et al. Low bone mineral density in adults with cystic fibrosis. Thorax 1999;54:961-7.

3 Conway SP, Morton AM, Oldroyd B, et al. Osteoporosis and osteopenia in adults and adolescents with cystic fibrosis: prevelance and associated factors. Thorax 2000;55:798-804

4 Aris RM, Stephens AR, Onties DA, et al. Adverse alterations in bone metabolism are associated with lung infection in adults with cystic fibrosis. Am J Respir Crit Care Med 2000;162:1674-8.

5 lonescu AA, Nixon LS, Evans WD, et al. Bone density, body composition and inflammatory status in cystic fibrosis. Am J Respir Crit Care Med 2000;162:789-94.

6 Henderson RC, Specter BB. Kyphosis and fractures in children and young adults with cystic fibrosis. J Pediatr 1994;125:208-12.

7 Aris RM, Renner JB, Winders AD, et al. Increased rate of fractures and severe kyphosis: sequelae of living into adulthood with cystic fibrosis. Ann Intern Med 1998;128:186-93.

8 Aris RM, Neuringer IP, Weiner MA. Severe osteoporosis before and after lung transplantation. Chest 1996;109:1176-83.

9 Donovan DS, Papadopoulos A, Staron RB, et al. Bone mass and vitamin D deficiency in adults with advanced cystic fibrosis lung disease. Am J Respir Crit Care Med 1998; 157:1892-9.

10 Baroncelli GI, de Luca F, Magazzu G, et al. Bone demineralization in cystic fibrosis: evidence of imbalance between bone formation and degradation. Pediatr Res 1997:41:397-403.

11 Haworth CS, Webb AK, Egan JJ, et al. Bone histomorphometry in adult patients with cystic fibrosis. Chest 2000; 118:434-9.

12 Cranney A, Guyatto G, Krolick N, et al. A meta-analysis of etidronate for the treatment of postmenopausal osteoporosis. Osteoporosis Int $2001 ; 12: 140-51$

13 Homik J, Cranney A, Shea B, et al. Bisphosphonate for steroid induced osteoporosis (Cochrane Revew). In:The Cochrane Library. Issue 2. Chichester, UK: John Wiley \& Sons, 2001.

14 Truscott JG, Oldroyd B, Simpson M, et al. Variation in lumbar spine and femoral neck bone mineral measured by dual energy $x$-ray absorption: a study of 329 women. Br J Radiol 1993;66:514-21.

15 Woodrow G, Oldroyd B, Turney JH, et al. Influence of changes in peritoneal fluid on body composition measurements by dual-energy $x$-ray absorpitiometry in patients receiving continuous ambulatory peritoneal dialysis. Am J Clin Nutr 1996;64:237-41.

16 Oldroyd B, Milner R, Smith AH, et al. A total body phantom for use with lunar dual-energy X-ray absorptiometers. Appl Radiat Isot 1998;49:525-6.

17 Cruz DN, Brickel HM, Wysolmerski JJ, et al. Treatment of osteoporosis and osteopenia in long-term renal transplant patients with alendronate. Am J Transpl 2002;2:62-7.

18 Sood M, Hambleton G, Super M, et al. Bone status in cystic fibrosis. Arch Dis Child 2001;84:516-20. 
19 Hardin DS, Arumugam R, Seilheimer DK, et al. Normal bone density in cystic fibrosis. Arch Dis Child 2001;84:363-8.

20 Haworth CS, Selby PL, Horrocks AW, et al. A prospective study of change in bone mineral density over one year in adults with cystic fibrosis. Thorax 2002;57:719-23.

21 Manalogas SC. Birth and death of bone cells: basic regulatory mechanisms and implications for the pathogenesis and treatment of osteoporosis. Endocr Rev 2000;21:115-37.

22 Reinholz GG, Getz B, Pederson L, et al. Bisphosphonates directly regulate cell proliferation, differentiation, and gene expression in human osteoblasts. Cancer Res 2000;60:6001-7.

23 Haworth CS, Selby PL, Adams JE, et al. Effect of intravenous pamidronate on bone mineral density in adults with cystic fibrosis. Thorax $2001 ; 56: 314-6$.
24 Aris RM, Lester GE, Renner JB. Efficacy of pamidronate for osteoporosis in patients with cystic fibrosis following lung transplantation. Am J Respir Crit Care Med 2000;162:941-6.

25 Tothill $P$, Pye DW. Errors due to non-uniform distribution of fat in dual $x$-ray absorptiometry of the lumbar spine. Br J Radiol 1992:65:807-13.

26 Peel NFA, Eastell R. Comparison of rates of bone loss from the spine measured using two manufacturers' densitometers. J Bone Min Res 1995; 10:1796-801.

27 Tothill P, Avenell A. Anomalies in the measurement of changes in bone mineral density of the spine by dual-energy $x$-ray absorptiometry. Calcif Tissue Int 1998:63:126-33.

28 Tothill P, Laskey MA, Orphanidou $\mathrm{Cl}$, et al. Anomalies in dual energy x-ray absorptiometry measurements of total-body bone mineral during weight change using Lunar, Hologic and Norland instruments. Br J Radiol 1999;72:661-9.

\section{LUNG ALERT}

\section{Beneficial effects of omalizumab in patients with concomitant asthma and persistent allergic rhinitis}

$\Delta$ Vignola AM, Humbert M, Bousquet J, et al. Efficacy and tolerability of anti-immunoglobulin $E$ therapy with omalizumab in patients with concomitant allergic asthma and persistent allergic rhinitis: SOLAR. Allergy 2004;59:709-17

T

he link between allergic inflammation of the upper and lower airways is well established with up to $40 \%$ of asthmatics considered to have concomitant allergic

rhinitis. In addition to cysteinyl leukotrienes and histamine, immunoglobulin E (IgE) is implicated in allergic inflammation which suggests that modalities directed against such molecules could play an important role towards treatment of the unified airway.

Vignola et al investigated moderate to severe asthmatics with concomitant persistent allergic rhinitis $(\mathrm{n}=405)$ in a multicentre, randomised, double blind, placebo controlled, parallel group study. They evaluated the effects of anti-IgE therapy with omalizumab (in addition to inhaled or nasal corticosteroids) in terms of primary end points of exacerbations of asthma and changes in disease related quality of life. Inclusion criteria included an IgE level of 30-1300 IU/ml plus at least one positive skin prick test to indoor allergens. Fewer patients experienced an asthma exacerbation with omalizumab than with placebo $(21 \% \mathrm{v}$ $30 \%, p=0.02$ ), and a greater proportion of patients on omalizumab than on placebo showed improvement in both asthma and rhinitis quality of life questionnaires $(58 \% \vee 41 \%$, $\mathrm{p}<0.001)$. There was no difference in serious adverse effects.

Despite a marked placebo effect, the authors conclude that omalizumab, when used in combination with standard treatment, is effective in reducing exacerbations of asthma and confers clinically relevant improvements in quality of life. The effectiveness and "real life" acceptability of omalizumab injections remain to be established. Moreover, how omalizumab compares with pharmacotherapy attenuating the effects of cysteinyl leukotrienes and histamine in allergic airways disease requires evaluation.

G P Currie

Specialist Registrar in Respiratory Medicine, Aberdeen Royal Infirmary, Foresterhill, Aberdeen, UK; graeme_currie@yahoo.com 